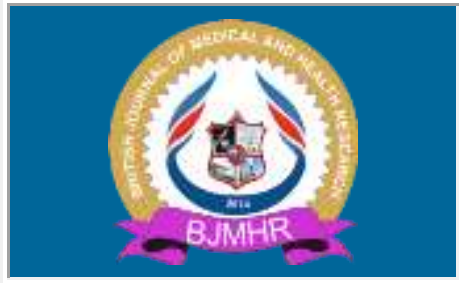

\title{
BJMHR
}

British Journal of Medical and Health Research Journal home page: www.bjmhr.com

\section{The Effect of Exercise on Arterial Blood Gases in Chronic Obstructive Pulmonary Disease}

\section{Hakan Celikhisar ${ }^{1}$, Gulay Dasdemir Ilkhan ${ }^{2}$}

1.Esrefpasa Metropolitan Municipality Hospital, Chest Diseases Clinic. Chest Diseases Specialist, Izmir University of Economics, Vocational School of Health Science, Gaziler Caddesi No:315, 35110; IZMIR- TURKEY.

2.Okmeydanı Education and Research Hospital, Chest Diseases Clinic. Chest Diseases Specialist. Okmeydanı, Istanbul- TURKIYE

\section{ABSTRACT}

It is important in the present day to ensure that the social activities of COPD patients are carried out without any problem as part of the goals of approach to and treatment of COPD patients for minimizing both labor loss and financial losses. The use of socioeconomic and demographic characteristics of COPD patients as a tool during their assessment is increasing in importance. Hence, the purpose of the present study was to examine the impact of exercise on blood gases in COPD patients. A total of 378 patients with ages ranging between 45 and 82 who have applied to the pulmonary diseases polyclinic and emergency of our hospital or who have been admitted to the clinic during March 2019 and December 2019 were included in this prospective study. All of the 160 patients with emphysema and 218 patients with chronic bronchitis were stable. Cases with accompanying diseases other than respiratory system disorders (cardiac, diabetes mellitus etc.) and patients in acute attack were excluded from the study. Of our cases, $180(47.62 \%)$ were female and $198(52.38 \%)$ were male with an age average of 60.95 \pm 5.7 . End of exercise respiratory rate increase, (p:0.003), $\mathrm{PaO} 2$ increase (p:0.008), $\mathrm{PaCO} 2$ increase (p:0.005) and $\mathrm{pH}$ decrease (p:0.009) were observed to be statistically significant in chronic bronchitis predominant patients. End of exercise respiratory rate increase (p:0.006) along with decreases in $\mathrm{pH}$ (p:0.008) and $\mathrm{PaO} 2$ (p:0.009) were observed to be statistically significant in emphysema predominant patients. Exercise training is important for the rehabilitation of COPD patients and increases their quality of life. Hence, we concluded that that it may be beneficial to determine the end of exercise blood gases of stable COPD patients for planning their residential treatment.

Keywords: Chronic Obstructive Pulmonary Disease, exercise, arterial blood gas 


\section{INTRODUCTION}

Blood gas anomalies chronic obstructive pulmonary disease (COPD) may worsen during acute attacks, sleep and exercise (1). It is known that maximum exercise performance and exercise tolerance are lower for these patients compared to healthy individuals at the same age and gender. Physical exercise means increased metabolic rate. Oxygen generation and carbon dioxide consumption increases in all muscles involved in addition to an increased requirement for oxygen in these muscles as well as the requirement to remove the generated carbon dioxide (2). This may lead to clinical complaints in the patient under effort. Measuring the gas change is important for individuals with cardiopulmonary diseases since the symptoms that develop with exercise are at the forefront (3). However, the duration of the exercise, its intensity, type, age of the patient, body weight and physical form affect the evaluation of the response to the exercise.

Exercise in healthy individuals increases ventilation by increasing both tidal volume and respiratory rate. Tidal volume is stabilized at about 50-60\% of the vital capacity during activities that require greater effort and the increases in minute ventilation are only subject to the increased respiratory rate. Indeed, tidal volume may even decrease with increasing minute ventilation during periods of extreme effort. The same is true for COPD as well. However, tidal volume is much lower and respiratory frequency is much greater in comparison with healthy individuals at similar minute ventilation levels (4). It has been reported in various studies for emphysema predominant cases that partial oxygen pressure $(\mathrm{PaO} 2)$ decreases with exercise, while $\mathrm{PaO} 2$ has been reported to increase in cases without emphysema predominance (5). Lack of an improvement in diffusion capacity of emphysema patients with exercise is typical for emphysema and hypoxemia increases with exercise while it may recover for those with chronic bronchitis. However, the same case is not valid for every patient (6). While hypoxia may develop in emphysema subject to the increase in the dead space volume/tidal volume, $\mathrm{PaO} 2$ may remain constant, may increase or decrease in chronic bronchitis subject to the change in the ventilation/perfusion (V/Q) ratio (7).

The use of exercise tests in assessing the patient has increased in recent years. Thus, the purpose of the study was to examine the impacts of exercise on blood gases in COPD patients.

\section{MATERIALS AND METHOD}

A total of 378 patients with ages ranging between 45 and 82 who have applied to the pulmonary diseases polyclinic and emergency of our hospital or who have been admitted to the clinic during March 2019 and December 2019 were included in this study. Of the participants, 198 were male and 180 were female. In total, 160 had emphysema and 218 had chronic bronchitis and all were stable. All chronic bronchitis patients were stable. The patients were classified as 
168 emphysema predominant patients and 210 chronic bronchitis predominant patients subject to the findings of anamnesis, physical examination, chest radiography, arterial blood gas and thoracic computerized tomography. The $\mathrm{PaO} 2$ level was above $55 \mathrm{mmHg}$ in all patients and cases with ischemic heart diseases or cor pulmonale symptoms were excluded from the study. Respiratory function test was applied on the patients at rest prior to the exercise. Blood was drawn from the brachial and radial arteries after which blood gas analyses were carried out via radiometer ABL 300 blood gas analyzer.

The patients were then asked to exercise for at most up to 5 minutes at the Monark 810 bicycle ergonomics until the onset of dyspnea and/or fatigue. The patients were monitored via ECG during this process. Blood gas analysis was repeated after the exercise was completed. The acquired data were recorded and statistical analyses were carried out.

\section{Statistics}

NCSS (Number Cruncher Statistical System) 2017 (Kaysville, Utah, USA) was used for statistical analysis. Descriptive statistical methods (frequency, percentage) were used to evaluate the study data. Pearson chi-square test and Fisher-Freeman-Halton exact test were used to compare the qualitative data. The characteristics of the patients were determined by correlation and student-t test. Statistical significance was accepted as $\mathrm{p}<0.05$.

\section{RESULTS AND DISCUSSION}

Of our cases, $180(47.62 \%)$ were female, 198 (52.38\%) were male with an age average of $60.95 \pm 5.7$. It was observed when both groups were compared together that end of exercise $\mathrm{PaCO} 2$ and respiratory rate increase along with $\mathrm{pH}$ decrease were statistically significant $(p<0.01)$ whereas the increase in $\mathrm{paO} 2$ was not statistically significant $(\mathrm{p}>0.05)$.

Of the patients with emphysema and chronic bronchitis included in the study, there were no statistically significant differences with regard to the numbers of female and males and their ages (p:0.1 and p:0.2 respectively).

It was observed when patients with chronic bronchitis and emphysema were compared with regard to vital capacities that the emphysema patients have vital capacities that are greater at a statistically significant level (p:0.004).

End of exercise respiratory rate increase (p:0.003) $\mathrm{PaO} 2$ increase (p:0.008) PaCO2 increase (p:0.005) and $\mathrm{pH}$ decrease (p:0.009) were determined to be statistically significant in chronic bronchitis predominant patients with.

Whereas end of exercise respiratory rate increase (p:0.006), $\mathrm{pH}$ (p:0.008) and $\mathrm{PaO} 2$ decrease (p:0.009) were determined to be statistically significant in emphysema predominant patients. 
Table 1: Blood gas, Respiratory rate and Pulmonary function test values of patients

\begin{tabular}{llllll}
\hline & Total patient & Chronic bronchitis & p & emphysema & p \\
\hline Number of patients(n) & 378 & 210 & & 168 & \\
Age (median) & $59.2 \pm 5.40$ & $62,7 \pm 4,80$ & & $57.3 \pm 4.5$ & \\
FEV1 & $0.94 \pm 0.04$ & $0.75 \pm 0.05$ & & $1.08 \pm 0.05$ & \\
Vital capacity & $2.01 \pm 0.07$ & $1.81 \pm 0.01$ & & $2.18 \pm 0.09$ & 0.004 \\
Respiratory rate & & & & \\
Resting & $25.6 \pm 0.07$ & $27.8 \pm 1.10$ & 0.003 & $24.0 \pm 0.80$ & 0.006 \\
End of exercise & $34.7 \pm 0.07$ & $32.4 \pm 0.80$ & & $37.5 \pm 1.30$ & \\
pH & & & & & \\
Resting & $7.38 \pm 0.00$ & $7.38 \pm 0.00$ & 0.007 & $7.39 \pm 0.00$ & 0.008 \\
End of exercise & $7.30 \pm 0.00$ & $7.30 \pm 0.01$ & & $7.30 \pm 0.01$ & \\
PaO2 (mmHg) & & & & & \\
Resting & $47.9 \pm 1.10$ & $47.6 \pm 1.30$ & 0.005 & $48.30 \pm 1.80$ & 0.004 \\
End of exercise & $51.7 \pm 1.50$ & $49.2 \pm 1.60$ & & $54.7 \pm 2.50$ & \\
PaO2 (mmHg) & & & & & \\
Resting & $67.9 \pm 1.20$ & $68.0 \pm 1.70$ & 0.008 & $67.7 \pm 2.10$ & 0.009 \\
End of exercise & $69.8 \pm 2.20$ & $78.6 \pm 2.40$ & & $58.8 \pm 3.00$ & \\
\hline
\end{tabular}

\section{DISCUSSION}

Measurement of blood gases during exercise aids in an objective assessment in those with suspicions related to the normality of respiratory and cardiac functions (8). It is more apparent that it will be more beneficial for determining the residential treatment of patients discharged with a $\mathrm{PaO} 2$ value of above 55-60 mmHg following treatment of COPD related respiratory failure. However, it is also indicated that the assessment of clinical symptoms during exercise is more beneficial compared to arterial blood gases (9). Impacts of blood exercise on the blood gases and spirometric measurements of COPD patients attract the attention of researchers.

Ejiofor et al. carried out exercise studies on patients with moderate and severe airway obstruction as a result of which the $\mathrm{PaO} 2$ level was determined to be low at a statistically significant level for the group with severe obstruction whereas a statistically insignificant increase was observed in $\mathrm{PaCO} 2$ in both groups. More severe anomalies were determined in VD/VT an $\mathrm{P}(\mathrm{A}-\mathrm{a}) \mathrm{O} 2$ (alveolar- arterial $\mathrm{O} 2$ gradient) in those with severe obstructive disorder (10).

Brightling et al. carried out an exercise on COPD patients classified into two groups based on emphysema and chronic bronchitis predominance as a result of which a decrease was reported in $\mathrm{PaO} 2$ values of both groups and an increase was reported in the $\mathrm{PaCO} 2$ values. The decrease in $\mathrm{PaO} 2$ was more distinct in the emphysema group which was concluded to be closely related with diffusion capacity (11).

Whereas Wells et al. carried out an exercise on moderate and severe COPD patients as a result of which decrease in $\mathrm{PaO} 2$ and increase in $\mathrm{PaCO} 2$ were reported However, they put forth that there are differences between the patients emphasizing that the difference in $\mathrm{PaO} 2$ is greater 
than $10 \mathrm{mmHg}$ in 5 patients, whereas $\mathrm{PaCO} 2$ changes in 8 patients are closely related with the response of $\mathrm{CO} 2$ against metabolic generation, level of mechanical disorder, VD/VT ratio and the $\mathrm{O} 2$ levels in arterial blood (12).

Arslan et al. reported a statistically significant increase in $\mathrm{PaO} 2$ at the end of exercise. It was determined as a result of the assessment of COPD patients subject to disability that spirometric and arterial blood gas findings at the end of exercise do not have a statistically significant impact on the values acquired while at rest (13).

It is known that acidosis takes place in normal people and those with cardiovascular diseases during exercise. Metabolic acidosis developed in COPD patients which is more distinctive for patients with advanced limitations on exercise. This puts forth that acidosis in these patients is related mostly to extremity muscles rather than respiratory muscles (14).

$\mathrm{PaO} 2$ increase, $\mathrm{pH}$ decrease, $\mathrm{PaCO} 2$ increase in the chronic bronchitis predominant group along with $\mathrm{PaO} 2$ decrease, $\mathrm{pH}$ decrease and $\mathrm{PaCO} 2$ increase in the emphysema predominant group were determined to be statistically significant. In case there is an increase in the P(A-a) $\mathrm{O} 2$ difference at rest, this may be improved or further regressed subject to whether a uniform V/Q distribution is obtained as a result of cardiac flow rate and ventilation. VD/VT ratio generally decreases despite the increase in physiologic dead space following the increase in respiratory volume. This is an indication that regions with greater ventilation-perfusion ratio receive greater amounts of blood flow. Hence, $\mathrm{PaO} 2$ and $\mathrm{P}(\mathrm{A}-\mathrm{a}) \mathrm{O} 2$ difference may improve during exercise (15). $\mathrm{PaO} 2$ may decrease when there is no increase in diffusion capacity in emphysema (16). Whereas hypercapnia is related with the respiratory response to metabolic acidosis in addition to the increase in VD/VT ratio and respiratory work (17).

Exercise training is important for the rehabilitation of COPD patients and increases their quality of life (18). . Hence, we are of the opinion that it may be beneficial to determine the end of exercise blood gases of stable COPD patients for planning their residential treatment.

\section{REFERENCES}

1. Mason RJ, Broaddus VC, Martin TR, King T, Schraufnagel D. Murray and Nadel's textbook of respiratory medicine: Elsevier Saunders; 2010.

2. Behnia M, Wheatley CM, Avolio A, Johnson BDJNO. Influence of dietary nitrate supplementation on lung function and exercise gas exchange in COPD patients. 2018;76:53-61.

3. Dilektasli AG, Porszasz J, Stringer WW, Casaburi RJCicm. Physiologic effects of oxygen supplementation during exercise in chronic obstructive pulmonary disease. 2019;40(2):385-95. 
4. Smith BM, Jensen D, Brosseau M, Benedetti A, Coxson HO, Bourbeau JJSr. Impact of pulmonary emphysema on exercise capacity and its physiological determinants in chronic obstructive pulmonary disease. 2018;8(1):1-10.

5. Calverley PM. AJRCCM: 100-year anniversary. Physiology and chronic obstructive pulmonary disease in the blue journals. American Thoracic Society; 2017.

6. Miller M, Slootsky M, Patel RA, Mert M, Baydur AJOJoRD. Relation of Indices of Lung Hyperinflation to Dyspnea in Patients with Chronic Obstructive Pulmonary Disease: A Physiologic Assessment and Discussion. 2019;9(03):75.

7. Kitaoka HJJoFS, Technology. Reconstruction of respiratory physiology based on flow dynamics. 2018;13(4):JFST0023-JFST.

8. O'Donnell DE, Elbehairy AF, Webb KA, Neder JAJAotATS. The link between reduced inspiratory capacity and exercise intolerance in chronic obstructive pulmonary disease. 2017;14(Supplement 1):S30-S9.

9. Hoiland RL, Mladinov S, Barak OF, Willie CK, Mijacika T, Stembridge M, et al. Oxygen therapy improves cerebral oxygen delivery and neurovascular function in hypoxaemic chronic obstructive pulmonary disease patients. 2018;103(8):1170-7.

10. Ejiofor SI. The role of ambulatory oxygen to improve skeletal muscle gene expression in Chronic Obstructive Pulmonary Disease in patients with exercise induced hypoxaemia: University of Birmingham; 2018.

11. Brightling CE, editor Chronic obstructive pulmonary disease phenotypes, biomarkers, and prognostic indicators. Allergy Asthma Proc; 2016.

12. Wells JM, Estepar RSJ, McDonald M-LN, Bhatt SP, Diaz AA, Bailey WC, et al. Clinical, physiologic, and radiographic factors contributing to development of hypoxemia in moderate to severe COPD: a cohort study. 2016;16(1):169.

13. Arslan S, Yildiz G, Özdemir L, Kaysoydu E, Özdemir BJTKjoim. Association between blood pressure, inflammation and spirometry parameters in chronic obstructive pulmonary disease. 2019;34(1):108.

14. Hosseininia S, Aliasgharzadeh-Khiavi S, Zamani B, Habibzadeh A, Kheirjo S, Sadeghieh-Ahari SJJoARiCM. The relationship between acidosis and hypercapnia with Cor pulmonale in patients with chronic obstructive pulmonary disease. 2017;5(4):12833.

15. Neder JA, Berton DC, Müller PdT, Elbehairy AF, Rocha A, Palange P, et al. Ventilatory inefficiency and exertional dyspnea in early chronic obstructive pulmonary disease. 2017;14(Supplement 1):S22-S9.

16. Hwang HJ, Lee SM, Seo JB, Lee JS, Kim N, Kim C, et al. Assessment Of Changes In Regional Xenon-Ventilation, Perfusion, And Ventilation-Perfusion Mismatch Using 
Dual-Energy Computed Tomography After Pharmacological Treatment In Patients With Chronic Obstructive Pulmonary Disease: Visual And Quantitative Analysis. 2019;14:2195.

17. Mendez Y, Ochoa-Martinez FE, Ambrosii TJCRMR. Chronic Obstructive Pulmonary Disease and Respiratory Acidosis in the Intensive Care Unit. 2019;15(2):79-89.

18. Mohammed J, Derom E, Van Oosterwijck J, Da Silva H, Calders PJP. Evidence for aerobic exercise training on the autonomic function in patients with chronic obstructive pulmonary disease (COPD): a systematic review. 2018;104(1):36-45.

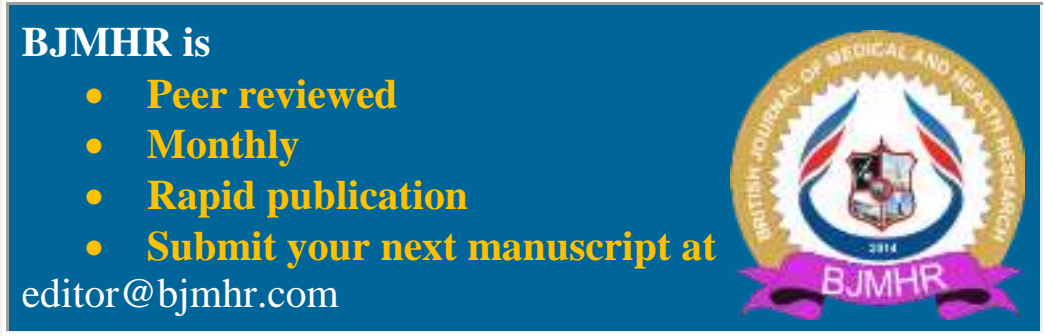

